\title{
Penatalaksanaan Fisioterapi Pada Anak Dengan Spinal Muscular Atrophy: Literature Review
}

\author{
${ }^{1}$ Egalia Novika Hidayat, ${ }^{1}$ Adnan Faris Naufal
}

${ }^{1}$ Program Studi Fisioterapi, Fakultas Ilmu Kesehatan, Universitas Muhammadiyah Surakarta Jl.A. Yani Tromol Pos 1 Pabelan Kartasura Telp. (0271)717417 Fax. (0271) 715448 Surakarta 57162

Email: egalianovika2211@gmail.com

Tanggal Submisi: 02 September 2021; Tanggal Penerimaan: 03 Desember 2021

\begin{abstract}
ABSTRAK
Spinal Muscular Athrophy (SMA) adalah penyakit autosomal resesif yang terjadi akibat adanya delesi ataupun mutasi pada protein survival motor neuron (SMN). Tujuan penelitian ini adalah untuk mengetahui penanganan fisioterapi pada anak dengan SMA melalui tinjauan literatur. Metode yang digunakan adalah mencari sumber data menggunakan delapan mesin pencarian (Scholar, PubMed, Orphanet, PlosOne, Sage publication,BMC,PEDro dan Cochrane). Menggabungkan kata kunci dengan menggunakan pencarian "Spinal Muscular Athropy" atau "Spinal Muscular Atrophy and Physyical therapy. Hasilnya dari seratus jurnal yang di temukan, terdapat enam jurnal yang membahas penanganan fisioterapi pada kasus SMA beserta dosisnya.
\end{abstract}

Kata Kunci: Spinal Muscular Atrophy, Fisioterapi

\begin{abstract}
Spinal Muscular Atrophy (SMA) is an autosomal recessive disease that occurs due to deletions or mutations in the motor neuron survival protein (SMN). The purpose of this study was to determine the treatment of physiotherapy in children with high school through a literature review. The method used is to search for data sources using eight search engines (Scholar, PubMed, Orphanet, PlosOne, Sage publication, BMC, PEDro and Cochrane). Combine keywords using the search "Spinal Muscular Atrophy" or "Spinal Muscular Atrophy and Physyical therapy. The results of the hundred journals found, there are six journals that discuss the handling of physiotherapy in high school cases and their dosages.
\end{abstract}

Keywords: Spinal Muscular Atrophy, Physiotherapy

ISSN 2722-9610

E - ISSN 2722-9629

\section{Pendahuluan}

Spinal Muscular Atrophy (SMA) adalah kelainan yang diturunkan secara genetik yang disebabkan oleh degenerasi pada alpha motor neuron yang terletak di anterior horn pada spinal cord (Boyer, Bowerman, \& Kothary, 2010) akibat dari adanya delesi atau mutasi dari survival motot neuronl dan 2 (SMN1 \& SMN2) (O'Connor, 2017). Angka kejadian SMA adalah 1 dari 10.000 kelahiran dan diperikirakan terdapat 1 hingga 4 orang per 100.000 orang di dunia yang mengidap SMA, meskipun begitu belum terdapat jumlah pasti tentang angka kejadian SMA di Indonesia
(Lally et al., 2017), hal ini disebabkan oleh terbatasnya alat pemeriksaan serta ciri-ciri spesifik dari SMA.

Sebagai bagian dari penyakit neurodegenerative, SMA dibagi menjadi tiga tipe dengan SMA tipe I adalah bentuk kelainan paling parah dengan harapan hidup rendah (Iftikhar, Frey, Shohan, Malek, \& Mousa, 2021).Spinal Muscular Atrophy menyebabkan terjadinya kelemahan otot secara progresive termasuk kelemahan pada otot-otot pernafasan yang juga menjadi salah satu penyebab utama kematian pada anak yang mengidap SMA (Ramsey et al., 2017; Rose et al., 2018). 
Seiring berjalannya waktu tipe dari kasus SMA dibagi kedalam 5 jenis, diantaranya tipe 0 dengan perkiraan bertahan hidup kurang dari 6 bulan setelah lahir, gejala yang muncul adalah hipotina berat, dan gagal nafas. Pada tipe I (Kugelberg- Welander disease) gejala akan muncul di usia 0-6 bulan dengan perkiraan hidup kurang dari 2 tahun akibat gagal nafas dan tidak pernah bisa duduk. Anak dengan SMA tipe II (Dubowitz disease) akan menampakan gejala di usia 6-18 bulan berupa kelemahan otot tungkai bawah progresive serta keterbatasan dalam bernafas sebagian besar hanya mampu untuk duduk, dan maksimal hanya mampu untuk berdiri. Bentul selanjutnya adalah tipe III dan IV dengan gejala yang muncul diatas usia 18 bulan dan bisa hidup normal (Trabacca et al., 2020).

Perawatan SMA memerlukan peran dari berbagai disiplin ilmu kesehatan termasuk perawatan fisioterapi(Dunaway et al., 2016). Secara umum tujuan di berikannya tindakan fisioterapi adalah untuk menjaga agar tidak terjadi penurunan kekuatan otot secara progresif, mencegah kontraktur sejak dini, mencegah skoliosis, perawatan fungsi paru serta meningkatkan kemampuan aktifitas fungsional sesuai masing-masing tipe yang di derita oleh anak dengan SMA(Bulut et al., 2019; Mercuri et al., 2018).

Meskipun sebagian teknik fisioterapi sudah banyak digunakan, sebuah penelitian cochrane systematic review menyatakan bahwa latihan penguatan yang dikombinasikan dengan latihan aerobik masih belum memiliki dasar yang jelas dan kualitas pembuktiannya masih rendah, namun proses fisioterapi yang diberikan menunjukan hasil yang cukup baik dalam beberapa peningkatan kemampuan fungsional serta fungsi pernafasan(Bartels, Montes, Van Der Pol, \& De Groot, 2019). Mengingat perlu adanya penelitian lanjutan, tujuan dari literature review ini adalah untuk mensintesis bukti saat ini tentang apa saja penanganan fisioterapi yang dapat diberikan pada anak dengan spinal muscular atrophy.

\section{Metode Penelitian}

Penelitian dilakukan dengan mecari literature melalui beberapa sumber data (Google Scholar, PubMed, Orphanet Journal, PLoSONE, Sage publication,BMC,PEDro dan Cochrane Databased Systematic Review) dari berbagai tahun, pencarian dimulai pada 26 juli 2021. Strategi pencarian adalah dengan menggabungkan kalimat "Spinal Muscular Atrophy" ; 'Penanganan Fisioterapi' atau 'Modalitas Fisioterapi' pada 'Spinal Muscular Atrophy'.

Setelah dilakukan pencarian sumber data, jurnal disaring kembali dengan menganalisa judul serta dosis latihan yang di cantumkan di dalam jurnal untuk selanjutnya di kelompokan ke dalam sebuah tabel. Responden dalam penelitian berkisar pada usia 56-89 bulan, intervensi yang diberikan adalah multimodalitas brupa latihan yang berfokus pada latiahn aerobik, latihan penguatan serta menjaga postural. Alat ukur atau pemeriksaan yang digunakan adalah skala Hammersmith, GMFM, Oksimeter, PedsQL dan peak flow meter. Kriteria inklusi dalam pencarian artikel adalah artikel berisi full text dalam bahasa Inggris maupun Indonesia, artikel hanya terkait dengan manusia dan memiliki responden berupa anak dengan spinal muscular atrophy. Sedangkan kriteria eklusinya yaitu artikel tidak bersifat full text, artikel berbahasa lain selain bahasa Inggris dan Indonesia.

\section{Hasil}

Dari hasil pencarian didapat 100 jurnal yang membahas tentang spinal muscular atrophy. Artikel kemudian di saring termasuk duplikasi artikel, screening abstrak, full text dan flow chart.

Pada screening full text artikel di saring kembali dengan melihat kriteria inklusi dan eklusi yang telah di tentukan.Studi artikel di tinjau secara independent berdasarkan kriteria tersebut, kemudian pada saringan terakhir terdapat 6 artikel yang akan dilakukan tahap review akhir sesuai dengan flow chart seleksi literatur. 
Berdasarkan artikel yang telah di dapat untuk peninjauan lanjutan, selanjutnya dilakukan ekstraksi data untuk mengelompokan beberapa hal penting didalam artikel seperti judul, penulis, tahun terbit artikel, kriteria responden, dan intervensi fisioterapi beserta dosis dalam terapi tersebut yang dapat dilihat pada tabel 1 .

Hasil pencarian berdasarkan database $(\mathrm{n}=100)$

- Google Scholar $(\mathrm{n}=59)$

- PubMed (n=23)

- Orphanet $(n=4)$

- $\operatorname{PLoSONE}(=3)$

- Sage Publication $(n=6)$

- $\operatorname{BMC}(n=2)$

- Cochrane Database $(n=1)$

- $\operatorname{PEDro}(n=2)$

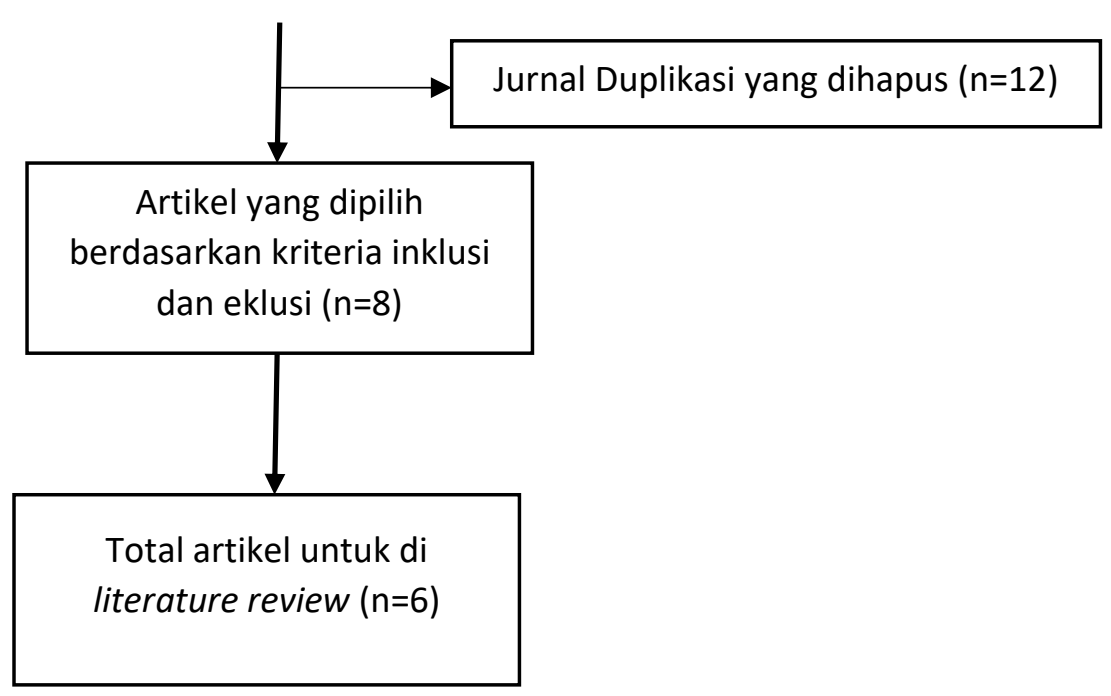

Skema 1.1 Flowchart 
Table 1.

Karakteristik Penelitian

\begin{tabular}{|c|c|c|c|c|}
\hline No & Judul Penelitian & Penulis & Responden & Intervensi \\
\hline 1 & $\begin{array}{l}\text { The effect of two different } \\
\text { aerobic training modalities } \\
\text { in a child with spinal } \\
\text { muscular atrophy type II: a } \\
\text { case report. }\end{array}$ & $\begin{array}{l}\text { Bulut et } \\
\text { al } \\
(2017)\end{array}$ & 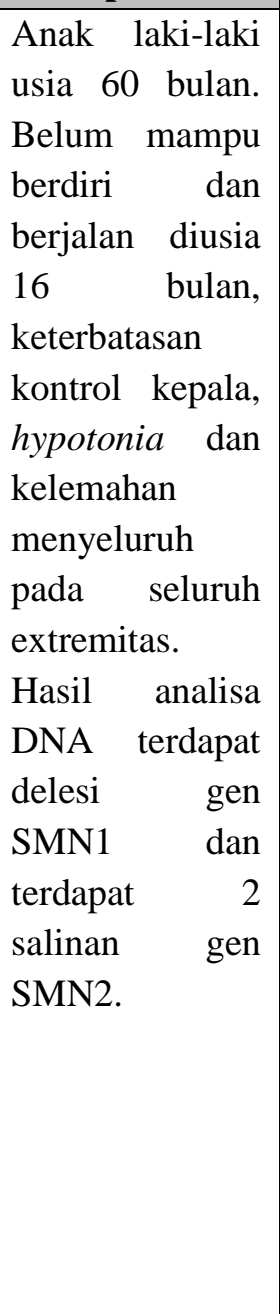 & 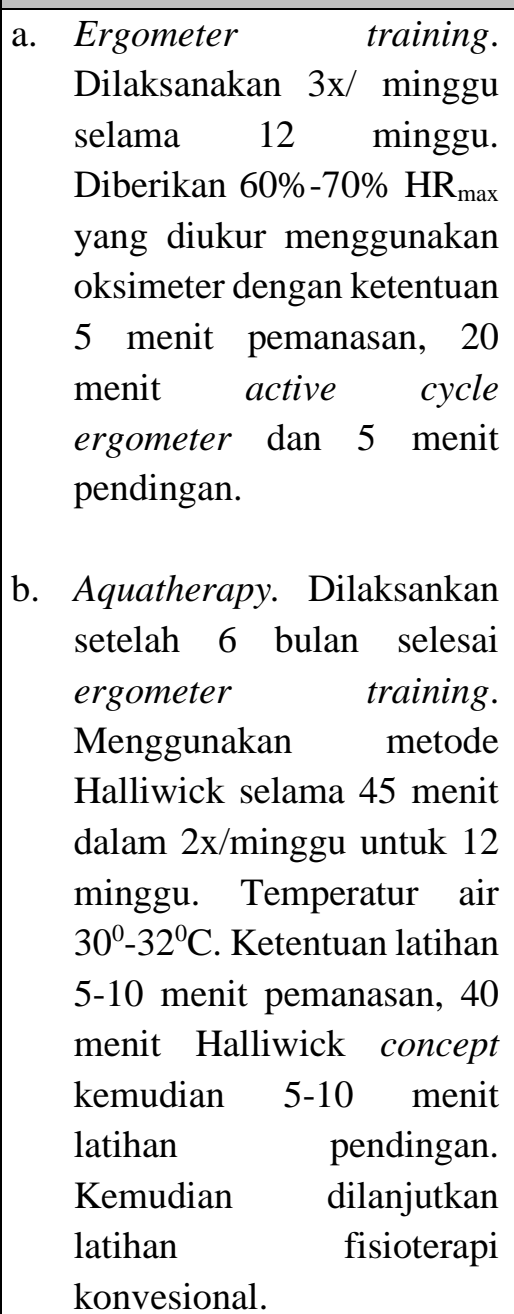 \\
\hline 2 & $\begin{array}{l}\text { Diagnosis and management } \\
\text { of spinal muscular atrophy : } \\
\text { part 2: Pulmonary and acute } \\
\text { care;medication,suplements } \\
\text { and immunization ; other } \\
\text { organ system; and ethics }\end{array}$ & $\begin{array}{l}\text { Finkel et } \\
\text { al } \\
(2018)\end{array}$ & $\begin{array}{l}\text { Anak dengan } \\
\text { spunal } \\
\text { muscular } \\
\text { atrophy parah } \\
\text { dan sedang } \\
\text { menjalani } \\
\text { pengobatan } \\
\text { (anak yang } \\
\text { mampu duduk } \\
\text { maupun tidak } \\
\text { mampu duduk ) }\end{array}$ & \begin{tabular}{|l} 
a. \\
Non-sitters : \\
membersihkan jalan nafas \\
dengan oral suction, \\
manual chest therapy, dan \\
latihan batuk yang \\
dievaluasi setiap 3 bulan \\
lalu 6 bulan. \\
b. Sitters : membersihkan \\
jalan nafas dengan oral \\
suction, manual chest \\
therapy, dan latihan batuk \\
yang dievaluasi setiap 6 \\
bulan.
\end{tabular} \\
\hline 3 & $\begin{array}{l}\text { Diagnosis and management } \\
\text { of spinal muscular atrophy: } \\
\text { part 1: Recomendation for } \\
\text { diagnosis,rehabilitation, }\end{array}$ & $\begin{array}{l}\text { Mercuri } \\
\text { et al } \\
(2018)\end{array}$ & $\begin{array}{l}\text { Anak dengan } \\
\text { spinal muscular } \\
\text { atrophy yang } \\
\text { mampu duduk, }\end{array}$ & $\begin{array}{|llrr|}\text { a. } & \text { Non-sitters } & \text { : } & \text { Kontrol } \\
& \text { postural } & & \text { dengan } \\
& \text { posisioning } & & \text { dan } \\
& \text { penggunaan } & \text { brace } & \text { berupa }\end{array}$ \\
\hline
\end{tabular}




\begin{tabular}{|c|c|c|c|c|}
\hline No & Judul Penelitian & Penulis & Responden & Intervensi \\
\hline & $\begin{array}{l}\text { orthopedic and nutritional } \\
\text { care }\end{array}$ & & $\begin{array}{l}\text { tidak mampu } \\
\text { duduk dan dapat } \\
\text { melakukan } \\
\text { ambulasi } \\
\text { (berjalan) }\end{array}$ & $\begin{array}{l}\text { orthoses yang diaplikasikan } \\
>60 \text { menit setiap malam, } \\
\text { Stretching } \\
\text { menggunakan } \mathrm{AFO}_{\mathrm{s}} \text { dan } \\
\mathrm{KAFO}_{\mathrm{s} \text { yang }} \text { juga } \\
\text { digunakan } \\
\text { positioning, sebagai } \\
\text { penggunaan } \\
\text { frequensi latihan } \\
\text { 5x/minggu. dengan } \\
\text { standing Supported } \\
\text { physiotherapy. dan chest }\end{array}$ \\
\hline & & & & $\begin{array}{l}\text { b. Sitters: Kontrol postural } \\
\text { dengan bracing dan } \\
\text { positioning menggunakan } \\
\text { orthoses >60 menit setiap } \\
\text { malam, penanganan } \\
\text { skoliosis dan pelvic yang } \\
\text { asimetris dengan bracing } \\
5 \mathrm{x} / \text { minggu, stretching 5- } \\
7 \mathrm{x} / \text { minggu, supported } \\
\text { standing diatas } 60 \text { menit } \\
\text { dengan frekuensi } 3- \\
5 \mathrm{x} / \text { minggu, optimalnya 5- } \\
7 \mathrm{x} / \text { minggu, peningkatan } \\
\text { aktifitas fungsional dan } \\
\text { mobilitas dengan latihan } \\
\text { yang berfokus pada fungsi, } \\
\text { kekuatan, ROM, daya } \\
\text { tahan, ADL, partisipasi dan } \\
\text { keseimbangan yang } \\
\text { direkomendasikan dengan } \\
\text { berenang, hippotherapy dan } \\
\text { bantuan kursi roda dan } \\
\text { chest physiotherapy. }\end{array}$ \\
\hline & & & & $\begin{array}{l}\text { Walking: Peningkatan } \\
\text { fungsi dan mobilitas } \\
\text { direkomendasikan dengan } \\
\text { aerobik dan latihan dalam } \\
\text { kondisi umum untuk pasien } \\
\text { SMA yang mampu berjalan } \\
\text { seperti berenang, berjalan, } \\
\text { bersepeda , yoga, } \\
\text { hippotherapy yang diawasi }\end{array}$ \\
\hline
\end{tabular}




\begin{tabular}{|c|c|c|c|c|}
\hline No & Judul Penelitian & Penulis & Responden & Intervensi \\
\hline & & & & $\begin{array}{l}\text { dan di desain oleh terapi } \\
\text { fisik dengan durasi latihan } \\
30 \text { menit, stretching 2- } \\
3 \mathrm{x} / \text { minggu atau optimalnya } \\
3-5 \mathrm{x} / \text { minggu, dan } \\
\text { postioning and bracing }\end{array}$ \\
\hline 4 & $\begin{array}{l}\text { Effect of Arm Cycling } \\
\text { Exercise in Spinal Muscular } \\
\text { Atrophy Types II Patients: } \\
\text { A Pilot Study }\end{array}$ & $\begin{array}{l}\text { Bora et } \\
\text { al, } 2018\end{array}$ & $\begin{array}{l}\text { Anak usia 59-89 } \\
\text { bulan yang di } \\
\text { diagnosa SMA } \\
\text { tipe } 2 \text { dan tidak } \\
\text { dapat berdiri } \\
\text { maupun } \\
\text { berjalan namun } \\
\text { mampu duduk } \\
\text { secara mandiri } \\
\text { dan kooperatif }\end{array}$ & $\begin{array}{l}\text { Selama } 12 \text { minggu pasien akan } \\
\text { melakukan latihan dengan arm- } \\
\text { cycle ergometer dalam } 60 \% \\
\mathrm{HR}_{\max } \text { yang diukur } \\
\text { menggunakan pulse oximeter. } \\
\text { Latihan pada extremitas atas } \\
\text { dilakukan } 3 \mathrm{x} / \text { minggu setiap } \\
\text { sesi sudah termasuk } 5 \text { menit } \\
\text { pemanasan dan pendinginan } \\
\text { dengan total durasi activ dan } \\
\text { pasive cycling selama } 30 \\
\text { menit. }\end{array}$ \\
\hline 5 & $\begin{array}{l}\text { Vibration-Assited Home } \\
\text { Training Program for Child } \\
\text { With Spinal Muscular } \\
\text { Atrophy }\end{array}$ & $\begin{array}{l}\text { Stark et } \\
\text { al, } 2018\end{array}$ & $\begin{array}{l}\text { Sebanyak } 38 \\
\text { anak yang di } \\
\text { diagnosa } \\
\text { mengalami } \\
\text { SMA tipe II dan } \\
\text { III, minimal } \\
\text { memenuhi } \\
\text { pemeriksaan } \\
\text { pada } 1 \text { alat ukur } \\
\text { (GMFM-66 dan } \\
\text { Hammersmith) }\end{array}$ & $\begin{array}{l}\text { Menggabungkan } 2 \text { program } \\
\text { berupa program saat rawat inap } \\
\text { dan latihan dirumah. Saat rawat } \\
\text { inap latihan terdiri dari } 4-5 \text { jam } \\
\text { latihan fisioterapi harian } \\
\text { ditambah latihan tahanan, } \\
\text { latihan dikolam ,dan latihan } \\
\text { dengan treadmill 2-3x/minggu. } \\
\text { Setelah } 13 \text { hari latihan dalam } \\
\text { masa rawat inap, pasien } \\
\text { melakukan side alternanting } \\
\text { whole body vibration } \\
\text { 10x/minggu selama } 3 \text { menit } \\
\text { dalam waktu } 3 \text { bulan, } \\
\text { kemudian melakukan } \\
\text { perawatan kembali selama } 6 \\
\text { hari dan latihan dirumah } 3 \\
\text { bulan. }\end{array}$ \\
\hline 6 & $\begin{array}{l}\text { Rehabilitation of } \text { spinal } \\
\text { muscular atrophy: current } \\
\text { consensus and future } \\
\text { direction }\end{array}$ & $\begin{array}{lr}\text { Yi } & \text { You } \\
\text { et } & \text { al, } \\
2020 & \end{array}$ & $\begin{array}{lr}\text { Anak dengan } \\
\text { diagnosa SMA } \\
\text { tipe I,II, dan III } \\
\text { (tidak mampu } \\
\text { duduk, mampu } \\
\text { duduk } \\
\text { mampu } \\
\text { berjalan) }\end{array}$ & $\begin{array}{l}\text { a. Positioning and bracing } \\
\text { dapat menggunakan head } \\
\text { and neck collar,spinal } \\
\text { orthoses, hand splints yang } \\
\text { direkomendasikan untuk } \\
\text { stretching dan positioning. } \\
\text { Lower limb orthoses untuk } \\
\text { ankle dan knee dapat } \\
\text { digunakan 5x/mingu }\end{array}$ \\
\hline
\end{tabular}




\begin{tabular}{|c|c|c|c|c|}
\hline No & Judul Penelitian & Penulis & Responden & Intervensi \\
\hline & & & & 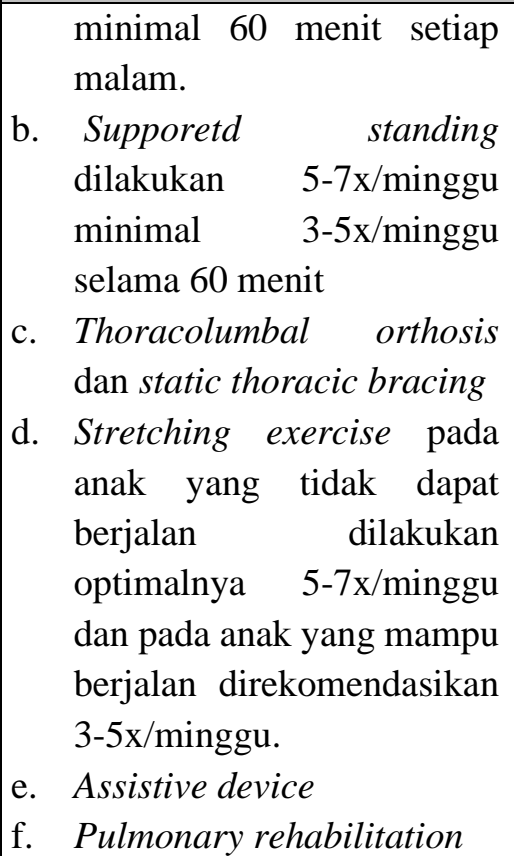 \\
\hline
\end{tabular}

\section{Pembahasan}

Pelayanan fisioterapi menjadi salah satu perawatan kesehatan yang cukup penting dalam kasus spinal muscular atrophy sebagai upaya untuk meminimalisir munculnya gejala yang semakin parah serta mempertahankan kemampuan fungsional paling maksimal yang dimiliki anak dengan SMA. Berdasarkan tinjauan literatur yang telah di saring dari 100 jurnal, terdapat 6 jurnal yang membahas cukup detail tentang perawatan anak dengan SMA beserta dosis latihan dalam pendekatan fisioterapi.

Sebagian besar fokus pembahasan dari ke enam jurnal yang di review adalah meneliti ke efektifan latihan dalam upaya meningkatkan fungsi paru, perbaikan postur,meningkatkan kekuatan otot serta meningkatkan kemampuan fungsional pada anak dengan SMA. Score pada skala Hammersmith dan GMFM menjadi tolak ukur utama dalam menilai kemampuan fungsional. Namun, meskipun hampir keseluruhan tujuan penelitian, bentuk latihan atau pemberian intervensi sama, semua masih memiliki kekurangan dan diperlukan penelitian lebih lanjut untuk mencapai kesepakatan dalam penyusunan guidline fisioterapi pada kasus SMA.
Menurut Bulut et al (2017) dalam study case nya menyatakan bahwa terdapat peningkatan nilai HMFM dan GMFM setelah di lakukan latihan aerobik dengan aquatic therapy dan ergometer training dalam hal ini aquatic therapy memiliki hasil yang lebih efektif. Begitupula dalam penelitian yang dilakukan oleh Bora et al (2018) menyebutkan bahwa nilai HMFM hanya mengalami sedikit peningkatan setelah dilakukan arm cycling exercise.

Selain hasil yang di dapat dari skala HMFM dan GMFM, upaya peningkatan kapasitas fungsi paru juga menjadi perhatian penting, mengingat penyebab kematian paling banyak pada anak dengan SMA adalah terjadinya gagal nafas. Sebagian besar peneliti menyatakan tidak banyak peningkatan yang ditemukan, khususnya pada SMA tipe I dan II yang tetap memerlukan bantuan dari mesin ventilator ataupun obat-obatan berupa nusinersen dan salbutamol untuk bernafas serta tidak adanya pengaruh pada quality of life pasien dengan SMA melalui penanganan fisioterapi.

\section{Kesimpulan}

Kesimpulan dari tinjauan literatur pada artikel ini menunjukan bahwa dasar perawatan 
fisioterapi masih belum jelas dan belum menemukan kesepakatan dalam protokol perawatan fisioterapi pada anak dengan semua tipe SMA. Hal ini disebabkan oleh banyak faktor seperti belum di temukannya cara maupun kesepakatan dalam menemukan frekuensi, intesitas serta lama pelaksanaan dari setiap latihan yang diberikan, selain itu penelitian masih di lakukan secara umum tanpa memperhatikan kesesuaian usia, gender maupun kondisi psikologis masing-masing anak dalam menjalani terapi. Namun dalam berbagai bentuk latihan yang telah di teliti sama-sama memiliki bukti adanya peningkatan pada kemampuan fungsional anak berdasarkan hasil penilaian skala HMFM dan GMFM khususnya pada anak tipe III dan IV yang mampu bertahan hidup dengan SMA sepanjang hidupnya.

\section{Referensi}

Aragon-Gawinska, K., Seferian, A. M., Daron, A., Gargaun, E., Vuillerot, C., Cances, C., ... Servais, L. (2018). Nusinersen in patients older than 7 months with spinal muscular atrophy type 1. Neurology. https://doi.org/10.1212/WNL.000000000 0006281

Arnold, W. D., Kassar, D., \& Kissel, J. T. (2015). Spinal muscular atrophy: Diagnosis and management in a new therapeutic era. Muscle and Nerve, 51(2), 157-167.

https://doi.org/10.1002/mus.24497

Baioni, M. T. C., \& Ambiel, C. R. (2010). Spinal muscular atrophy: Diagnosis, treatment and future prospects. Jornal de Pediatria.

https://doi.org/10.2223/JPED.1988

Bartels, B., Montes, J., Van Der Pol, W. L., \& De Groot, J. F. (2019). Physical exercise training for type 3 spinal muscular atrophy. Cochrane Database of Systematic Reviews. https://doi.org/10.1002/14651858.CD012 120.pub2

Boido, M., \& Vercelli, A. (2016). Neuromuscular junctions as key contributors and therapeutic targets in spinal muscular atrophy. Frontiers in Neuroanatomy.

https://doi.org/10.3389/fnana.2016.00006

Bharucha-Goebel, D., \& Kaufmann, P. (2017).

Treatment Advances in Spinal Muscular Atrophy. Current Neurology and Neuroscience Reports. https://doi.org/10.1007/s11910-0170798-y

Bishop, K. M., Montes, J., \& Finkel, R. S. (2018). Motor milestone assessment of infants with spinal muscular atrophy using the hammersmith infant neurological Exam-Part 2: Experience from a nusinersen clinical study. Muscle and Nerve, $\quad$ 57(1), 142-146. https://doi.org/10.1002/mus.25705

Bora, G., Yeşbek Kaymaz, A., Bekircan Kurt, C. E., Haliloğlu, V. G., Topaloğlu, H. A., Erdem Yurter, H., \& Erdem Özdamar, S. (2018). Recent therapeutic developments in spinal muscular atrophy. Turkish Journal of Medical Sciences. https://doi.org/10.3906/sag-1712-1

Bora, G., Subaşı-Yıldız, Ş., Yeşbek-Kaymaz, A., Bulut, N., Alemdaroğlu, İ., TuncaYılmaz, Ö., ... Erdem-Yurter, H. (2018). Effects of Arm Cycling Exercise in Spinal Muscular Atrophy Type II Patients: A Pilot Study. Journal of Child Neurology. https://doi.org/10.1177/08830738177505 00

Boyer, J. G., Bowerman, M., \& Kothary, R. (2010). The many faces of SMN: Deciphering the function critical to spinal muscular atrophy pathogenesis. Future Neurology. https://doi.org/10.2217/fnl.10.57

Bulut, N., Yardimci, B. N., Ayvat, E., Aran, O. T., Yilmaz, Ö., \& Karaduman, A. (2019). The effect of two different aerobic training modalities in a child with spinal muscular atrophy type II: A case report. Journal of Exercise Rehabilitation. https://doi.org/10.12965/jer.1836604.302 
Buu, M. C. (2017). Respiratory complications, management and treatments for neuromuscular disease in children. Current Opinion in Pediatrics, 29(3), 326-333.

https://doi.org/10.1097/MOP.000000000 0000498

Catteruccia, M., Vuillerot, C., Vaugier, I., Leclair, D., Azzi, V., Viollet, L., ... Quijano-Roy, S. (2015). Orthopedic Management of Scoliosis by Garches Brace and Spinal Fusion in SMA Type 2 Children. Journal of Neuromuscular Diseases. https://doi.org/10.3233/JND150084

Chen, H. (2017). Atlas of Genetic Diagnosis and Counseling. Atlas of Genetic Diagnosis and Counseling. https://doi.org/10.1007/978-1-49392401-1

Chen, T. H. (2020). New and developing therapies in spinal muscular atrophy: From genotype to phenotype to treatment and where do we stand? International Journal of Molecular Sciences, 21(9), 120. https://doi.org/10.3390/ijms21093297

Cuisset, J. M., \& Estournet, B. (2012). Recommendations for the diagnosis and management of typical childhood spinal muscular atrophy. Revue Neurologique, 168(12), 902-909. https://doi.org/10.1016/j.neurol.2012.07. 020

D'Amico, A., Mercuri, E., Tiziano, F. D., \& Bertini, E. (2011). Spinal muscular atrophy. Orphanet Journal of Rare Diseases. https://doi.org/10.1186/17501172-6-71

De Wel, B., Goosens, V., Sobota, A., Van Camp, E., Geukens, E., Van Kerschaver, G., ... Claeys, K. G. (2021). Nusinersen treatment significantly improves hand grip strength, hand motor function and MRC sum scores in adult patients with spinal muscular atrophy types 3 and 4 .
Journal of Neurology, 268(3), 923-935. https://doi.org/10.1007/s00415-02010223-9

Driscoll, S. W., \& Skinner, J. (2008). Musculoskeletal Complications of Neuromuscular Disease in Children. Physical Medicine and Rehabilitation Clinics of North America. https://doi.org/10.1016/j.pmr.2007.10.00 3

Droege, M., Sproule, D., Arjunji, R., GauthierLoiselle, M., Cloutier, M., \& Dabbous, O. (2020). Economic burden of spinal muscular atrophy in the United States: a contemporary assessment. Journal of Medical Economics, 23(1), 70-79. https://doi.org/10.1080/13696998.2019.1 646263

Dunaway, S., Montes, J., McDermott, M. P., Martens, W., Neisen, A., Glanzman, A. M., .. Pandya, S. (2016). Physical therapy services received by individuals with spinal muscular atrophy (SMA). Journal of Pediatric Rehabilitation Medicine, 9(1), 35-44. https://doi.org/10.3233/PRM-160360

Farrar, M. A., Park, S. B., Vucic, S., Carey, K. A., Turner, B. J., Gillingwater, T. H., ... Kiernan, M. C. (2017). Emerging therapies and challenges in spinal muscular atrophy. Annals of Neurology, 81(3), 355-368. https://doi.org/10.1002/ana.24864

Farrar, M. A., Vucic, S., Johnston, H. M., Du Sart, D., \& Kiernan, M. C. (2013). Pathophysiological insights derived by natural history and motor function of spinal muscular atrophy. Journal of Pediatrics, 162(1), 155-159. https://doi.org/10.1016/j.jpeds.2012.05.0 67

Fehlings, D. L., Kirsch, S., McComas, A., Campbell, K., \& Chipman, M. (2002). Evaluation of therapeutic electrical stimulation to improve muscle strength and function in children with types II/III spinal muscular atrophy. Developmental 
Medicine and Child Neurology. https://doi.org/10.1017/S0012162201002 869

Finkel, R. S., Chiriboga, C. A., Vajsar, J., Day, J. W., Montes, J., De Vivo, D. C., ... Bishop, K. M. (2016). Treatment of infantile-onset spinal muscular atrophy with nusinersen: a phase 2, open-label, dose-escalation study. The Lancet. https://doi.org/10.1016/S01406736(16)31408-8

Finkel, R. S., Mercuri, E., Meyer, O. H., Simonds, A. K., Schroth, M. K., Graham, R. J., ... Sejersen, T. (2018). Diagnosis and management of spinal muscular atrophy: Part 2: Pulmonary and acute care; medications, supplements and immunizations; other organ systems; and ethics. Neuromuscular Disorders. https://doi.org/10.1016/j.nmd.2017.11.00 4

Fischer, M. J., Asselman, F. L., Kruitwagenvan Reenen, E. T., Verhoef, M., Wadman, R. I., Visser-Meily, J. M. A., ... Schröder, C. D. (2020). Psychological well-being in adults with spinal muscular atrophy: the contribution of participation and psychological needs. Disability and Rehabilitation, 42(16), 2262-2270. https://doi.org/10.1080/09638288.2018.1 555864

Foead, A., Yeo, W. Y., Vishnumukkala, T., \& Larvin, M. (2019). Rehabilitation in spinal muscular atrophy. The Journal of the International Society of Physical and Rehabilitation Medicine. https://doi.org/10.4103/jisprm.jisprm_4_ 19

Francisco, G. E., \& Burke, D. (2019). The Journal of the International Society of Physical and Rehabilitation Medicine. 2(1498). https://doi.org/10.4103/jisprm.jisprm

Frongia, A. L., Natera-de Benito, D., Ortez, C., Alarcón, M., Borrás, A., Medina, J., ... Nascimento, A. (2019). Salbutamol tolerability and efficacy in patients with spinal muscular atrophy type II. Neuromuscular Disorders, 29(7), 517524.

https://doi.org/10.1016/j.nmd.2019.04.00 3

Fujak, A., Kopschina, C., Forst, R., Mueller, L. A., \& Forst, J. (2011). Use of orthoses and orthopaedic technical devices in proximal spinal muscular atrophy. Results of survey in 194 SMA patients. Disability and Rehabilitation: Assistive Technology. https://doi.org/10.3109/17483107.2010.5 25292

Fujak, A., Kopschina, C., Gras, F., Forst, R., \& Forst, J. (2011). Contractures of the lower extremities in spinal muscular atrophy type II. Descriptive clinical study with retrospective data collection. Ortopedia Traumatologia Rehabilitacja. https://doi.org/10.5604/15093492.933792

Glascock, J., Sampson, J., Haidet-Phillips, A., Connolly, A., Darras, B., Day, J., ... Jarecki, J. (2018). Treatment Algorithm for Infants Diagnosed with Spinal Muscular Atrophy through Newborn Screening. Journal of Neuromuscular Diseases. https://doi.org/10.3233/JND180304

Goodwin, A. M., Cornett, K. M. D., McKay, M. J., Burns, J., Garber, C. E., De Vivo, D. C., \& Montes, J. (2020). Limitations of 6minute walk test reference values for spinal muscular atrophy. Muscle and Nerve, 61(3), 375-382. https://doi.org/10.1002/mus.26794

Gormley, M. C. (2014). Respiratory management of spinal muscular atrophy type 2. Journal of Neuroscience Nursing. https://doi.org/10.1097/JNN.0000000000 000080

Hamilton, G., \& Gillingwater, T. H. (2013). Spinal muscular atrophy: Going beyond the motor neuron. Trends in Molecular Medicine.

https://doi.org/10.1016/j.molmed.2012.1 1.002 
Iannaccone, S. T., Hynan, L. S., Morton, A., Buchanan, R., Limbers, C. A., \& Varni, J. W. (2009). The PedsQL ${ }^{\mathrm{TM}}$ in pediatric patients with Spinal Muscular Atrophy: Feasibility, reliability, and validity of the Pediatric Quality of Life Inventory ${ }^{\mathrm{TM}}$ Generic Core Scales and Neuromuscular Module. Neuromuscular Disorders. https://doi.org/10.1016/j.nmd.2009.09.00 9

Iannaccone, S. T. (2007). Modern management of spinal muscular atrophy. Journal of Child Neurology, 22(8), 974-978. https://doi.org/10.1177/08830738073056 70

Iftikhar, M., Frey, J., Shohan, M. J., Malek, S., \& Mousa, S. A. (2021). Current and emerging therapies for Duchenne muscular dystrophy and spinal muscular atrophy. Pharmacology and Therapeutics, 220, 107719. https://doi.org/10.1016/j.pharmthera.202 0.107719

Jędrzejowska, M., \& Kostera-Pruszczyk, A. (2020). Spinal muscular atrophy - new therapies, new challenges. Neurologia $i$ Neurochirurgia Polska. https://doi.org/10.5603/PJNNS.a2019.00 68

Kariyawasam, D., Carey, K. A., Jones, K. J., \& Farrar, M. A. (2018). New and developing therapies in spinal muscular atrophy. Paediatric Respiratory Reviews. https://doi.org/10.1016/j.prrv.2018.03.00 3

Kaufmann, P., McDermott, M. P., Darras, B. T., Finkel, R., Kang, P., Oskoui, M., ... De Vivo, D. C. (2011). Observational study of spinal muscular atrophy type 2 and 3 : Functional outcomes over 1 year. Archives of Neurology, 68(6), 779-786. https://doi.org/10.1001/archneurol.2010.3 73

Kaufmann, P., McDermott, M. P., Darras, B. T., Finkel, R. S., Sproule, D. M., Kang, P. B., ... De Vivo, D. C. (2012). Prospective cohort study of spinal muscular atrophy types 2 and 3. Neurology. https://doi.org/10.1212/WNL.0b013e318 $271 \mathrm{f} 7 \mathrm{e} 4$

Kolb, S. J., \& Kissel, J. T. (2015). Spinal Muscular Atrophy. Neurologic Clinics. https://doi.org/10.1016/j.ncl.2015.07.004

Kolb, S. J., Ph, D., Coffey, C. S., Ph, D., Yankey, J. W., Ph, D., ... Kissel, J. T. (2017). Natural History of Infantile-Onset Spinal Muscular Atrophy. Annals of Neurology, 82(6), 883-891. https://doi.org/10.1002/ana.25101.Natura 1

Kruitwagen-van Reenen, E. T., van der Pol, L., Schröder, C., Wadman, R. I., van den Berg, L. H., Visser-Meily, J. M. A., \& Post, M. W. M. (2018). Social participation of adult patients with spinal muscular atrophy: Frequency, restrictions, satisfaction, and correlates. Muscle and Nerve, 58(6), 805-811. https://doi.org/10.1002/mus.26201

Lemke, D., Rothwell, E., Newcomb, T. M., \& Swoboda, K. J. (2014). Perceptions of equine-assisted activities and therapies by parents and children with spinal muscular atrophy. Pediatric Physical Therapy, 26(2), 237-244. https://doi.org/10.1097/PEP.0000000000 000027

Lally, C., Jones, C., Farwell, W., Reyna, S. P., Cook, S. F., \& Flanders, W. D. (2017). Indirect estimation of the prevalence of spinal muscular atrophy Type I, II, and III in the United States. Orphanet Journal of Rare Diseases, 12(1), 1-6. https://doi.org/10.1186/s13023-0170724-z

Livingstone, R., \& Paleg, G. (2021). Enhancing Function, Fun and Participation with Assistive Devices, Adaptive Positioning, and Augmented Mobility for Young Children with Infantile-Onset Spinal Muscular Atrophy: A Scoping Review and Illustrative Case Report. Disabilities, 1(1), $1-22$. 
https://doi.org/10.3390/disabilities10100 01

Lorson, C. L., Rindt, H., \& Shababi, M. (2010). Spinal muscular atrophy: Mechanisms and therapeutic strategies. Human Molecular Genetics, 19(R1), 111-118. https://doi.org/10.1093/hmg/ddq147

Lunn, M. R., \& Wang, C. H. (2008). Seminar: Spinal muscular atrophy. Lancet, 371, 2120-2133. Retrieved from www.thelancet.com

Mak, S. K. D., \& Accoto, D. (2021). Review of current spinal robotic orthoses. Healthcare (Switzerland), 9(1). https://doi.org/10.3390/healthcare901007 0

Mary, P., Servais, L., \& Vialle, R. (2018). Neuromuscular diseases: Diagnosis and management. Orthopaedics and Traumatology: Surgery and Research, 104(1), S89-S95. https://doi.org/10.1016/j.otsr.2017.04.019

Markowitz, J. A., Singh, P., \& Darras, B. T. (2012). Spinal muscular atrophy: A clinical and research update. Pediatric Neurology, 46(1), 1-12. https://doi.org/10.1016/j.pediatrneurol.20 11.09.001

Mazzone, E., Montes, J., Main, M., Mayhew, A., Ramsey, D., Glanzman, A. M., ... Mercuri, E. (2015). Old measures and new scores in spinal muscular atrophy patients. Muscle and Nerve, 52(3), 435-437. https://doi.org/10.1002/mus.24748

McGraw, S., Qian, Y., Henne, J., Jarecki, J., Hobby, K., \& Yeh, W. S. (2017). A qualitative study of perceptions of meaningful change in spinal muscular atrophy. BMC Neurology, 17(1), 1-9. https://doi.org/10.1186/s12883-0170853-y

Mercuri, E., Finkel, R. S., Muntoni, F., Wirth, B., Montes, J., Main, M., ... SzlagatysSidorkiewicz, A. (2018). Diagnosis and management of spinal muscular atrophy: Part 1: Recommendations for diagnosis, rehabilitation, orthopedic and nutritional care. Neuromuscular Disorders. https://doi.org/10.1016/j.nmd.2017.11.00 5

Montes, J., Gordon, A. M., Pandya, S., De Vivo, D. C., \& Kaufmann, P. (2009). Clinical outcome measures in spinal muscular atrophy. Journal of Child Neurology, 24(8), 968-978. https://doi.org/10.1177/08830738093327 02

Montes, J., Garber, C. E., Kramer, S. S., Montgomery, M. J., Dunaway, S., KamilRosenberg, S., ... De Vivo, D. C. (2015). Single-Blind, Randomized, Controlled Clinical Trial of Exercise in Ambulatory Spinal Muscular Atrophy: Why are the Results Negative? Journal of Neuromuscular Diseases, 2(4), 463-470. https://doi.org/10.3233/JND-150101

Montes, J., McDermott, M. P., Mirek, E., Mazzone, E. S., Main, M., Glanzman, A. M., ... Mercuri, E. (2018). Ambulatory function in spinal muscular atrophy: Agerelated patterns of progression. PLoS ONE, 13(6), 1-10. https://doi.org/10.1371/journal.pone.0199 657

Montes, J., Dunaway Young, S., Mazzone, E. S., Pasternak, A., Glanzman, A. M., Finkel, R. S., ... Farwell, W. (2019). Nusinersen improves walking distance and reduces fatigue in later-onset spinal muscular atrophy. Muscle and Nerve, 60(4), 409-414. https://doi.org/10.1002/mus.26633

Montes, J., Goodwin, A. M., McDermott, M. P., Uher, D., Hernandez, F. M., Coutts, K., ... De Vivo, D. C. (2021). Diminished muscle oxygen uptake and fatigue in spinal muscular atrophy. Annals of Clinical and Translational Neurology, 8(5), 1086-1095. https://doi.org/10.1002/acn3.51353

Nance, J. R. (2020). Spinal Muscular Atrophy. Continuum (Minneapolis, Minn.), 26(5), 1348-1368. 
https://doi.org/10.1212/CON.000000000 0000918

Nery, F. C., Siranosian, J. J., Rosales, I., Deguise, M. O., Sharma, A., Muhtaseb, A. W., ... Swoboda, K. J. (2019). Impaired kidney structure and function in spinal muscular atrophy. Neurology: Genetics, $5(5)$.

https://doi.org/10.1212/NXG.000000000 0000353

Nicolau, S., Waldrop, M. A., Connolly, A. M., \& Mendell, J. R. (2021). Spinal Muscular Atrophy. Seminars in Pediatric Neurology, 37(00168), 1-10. https://doi.org/10.1016/j.spen.2021.1008 78

Noto, Y. ichi, Misawa, S., Mori, M., Kawaguchi, N., Kanai, K., Shibuya, K., ... Kuwabara, S. (2013). Prominent fatigue in spinal muscular atrophy and spinal and bulbar muscular atrophy: Evidence of activity-dependent conduction block. Clinical Neurophysiology, 124(9), 1893-1898. https://doi.org/10.1016/j.clinph.2012.12.0 53

O'Connor, M. (2017). Use of Aquatic Based Physical Therapy in Treating an Adolescent with Severe Type II Spinal Muscle Atrophy: A Case Report. Doctor of Physical Therapy Program Case Reports. Retrieved from https://ir.uiowa.edu/pt_casereports/25

Parente, V., \& Corti, S. (2018). Advances in spinal muscular atrophy therapeutics. Therapeutic Advances in Neurological Disorders, 11, 1-13. https://doi.org/10.1177/17562856187545 01

Pera, M. C., Coratti, G., Mazzone, E. S., Montes, J., Scoto, M., De Sanctis, R., ... Mercuri, E. (2019). Revised upper limb module for spinal muscular atrophy: 12 month changes. Muscle and Nerve, 59(4), 426-430. https://doi.org/10.1002/mus.26419
Qian, Y., McGraw, S., Henne, J., Jarecki, J., Hobby, K., \& Yeh, W. S. (2015). Understanding the experiences and needs of individuals with Spinal Muscular Atrophy and their parents: A qualitative study. BMC Neurology, 15(1), 1-12. https://doi.org/10.1186/s12883-0150473-3

Quinn, L., \& Morgan, D. (2018). From Disease To Health: Physical Therapy Health Promotion Practices. J Neurol Phys Ther., 41, 1-18. https://doi.org/10.1097/NPT.0000000000 000166.From

Ramsey, D., Scoto, M., Mayhew, A., Main, M., Mazzone, E. S., Montes, J., ... Muntoni, F. (2017). Revised Hammersmith Scale for spinal muscular atrophy: A SMA specific clinical outcome assessment tool. PLoS ONE, 12(2), 1-19. https://doi.org/10.1371/journal.pone.0172 346

Rose, L., McKim, D., Leasa, D., Nonoyama, M., Tandon, A., Bai, Y. Q., ... Gershon, A. (2018). Respiratory health service utilization of children with neuromuscular disease. Pediatric Pulmonology, 53(10), 1378-1386. https://doi.org/10.1002/ppul.24145

Saadatmand, S., Vos, J. R., Hooning, M. J., Oosterwijk, J. C., Koppert, L. B., Bock, G. H. De, ... Chester, J. D. (2014). This article has been accepted for publication and undergone full peer review but has not been through the copyediting, typesetting, pagination and proofreading process which may lead to differences between this version and the Version of Record. Please c. The Laryngoscope, (2), 2-31.

Sasongko, T. H., Gunadi, Zilfalil, B. A., \& Zabidi-Hussin, Z. (2011). Deletion analysis of SMN1 exon 7 alone may be necessary and sufficient for the diagnosis of spinal muscular atrophy. Journal of Neurogenetics, 25(1-2), 15-16. https://doi.org/10.3109/01677063.2011.5 59561 
Schroth, M. K. (2009). Special considerations in the respiratory management of spinal muscular atrophy. Pediatrics, 123(SUPPL. 4). https://doi.org/10.1542/peds.2008-2952K

Scoto, M., Finkel, R. S., Mercuri, E., \& Muntoni, F. (2017). Therapeutic approaches for spinal muscular atrophy (SMA). Gene Therapy, 24(9), 514-519. https://doi.org/10.1038/gt.2017.45

Seidel, M. G. (2017). Autoimmunity in Patients with Primary Immunodeficiency. Up to Date, 33(4), 1-16. https://doi.org/10.1016/j.ncl.2015.07.004. Spinal

Stark, C., Duran, I., Cirak, S., Hamacher, S., Hoyer-Kuhn, H.-K., Semler, O., \& Schoenau, E. (2018). Vibration-Assisted Home Training Program for Children With Spinal Muscular Atrophy. Child Neurology Open, 5, 2329048X1878047. https://doi.org/10.1177/2329048x187804 77

Timmerberg, J. F., Krosschell, K. J., Young, S. D., Uher, D., Yun, C., \& Montes, J. (2021). Essential competencies for physical therapist managing individuals with spinal muscular atrophy: A delphi study. PLoS ONE, 16(4 April), 1-12. https://doi.org/10.1371/journal.pone.0249 279

Tisdale, S., \& Pellizzoni, L. (2015). Disease mechanisms and therapeutic approaches in spinal muscular atrophy. Journal of Neuroscience, 35(23), 8691-8700. https://doi.org/10.1523/JNEUROSCI.041 7-15.2015

Tizzano, E. F., \& Finkel, R. S. (2017). Spinal muscular atrophy: A changing phenotype beyond the clinical trials. Neuromuscular Disorders, 27(10), 883-889. https://doi.org/10.1016/j.nmd.2017.05.01 1

Townsend, E. L., Simeone, S. D., Krosschell, K. J., Zhang, R. Z., \& Swoboda, K. J. (2020). Stander Use in Spinal Muscular
Atrophy: Results from a Large Natural History Database. Pediatric Physical Therapy.

https://doi.org/10.1097/PEP.0000000000 000713

Trabacca, A., Lucarelli, E., Pacifico, R., Vespino, T., Di Liddo, A., \& Losito, L. (2020). The International Classification of Functioning, Disability and HealthChildren and Youth as a framework for the management of spinal muscular atrophy in the era of gene therapy: A proof-of-concept study. European Journal of Physical and Rehabilitation Medicine, 56(2), 243-251. https://doi.org/10.23736/S1973-

9087.20.05968-7

Vanoli, F., Rinchetti, P., Porro, F., Parente, V., \& Corti, S. (2015). Clinical and molecular features and therapeutic perspectives of spinal muscular atrophy with respiratory distress type 1. Journal of Cellular and Molecular Medicine, 19(9), 2058-2066. https://doi.org/10.1111/jcmm.12606

Van Alstyne, M., \& Pellizzoni, L. (2016). Advances in modeling and treating spinal muscular atrophy. Current Opinion in Neurology, 29(5), 549-556. https://doi.org/10.1097/WCO.000000000 0000368

Vega, P., Glisser, C., Castiglioni, C., Virginia Amézquita, M., Quirola, M., \& Barja, S. (2020). Quality of life in children and adolescents with spinal muscular atrophy. Revista Chilena de Pediatria, 91(4), 512520.

https://doi.org/10.32641/rchped.v91i4.14 43

Veerapandiyan, A., Eichinger, K., Guntrum, D., Kwon, J., Baker, L., Collins, E., \& Ciafaloni, E. (2020). Nusinersen for older patients with spinal muscular atrophy: A real-world clinical setting experience. Muscle and Nerve, 61(2), 222-226. https://doi.org/10.1002/mus.26769

Vuillerot, C., Payan, C., Iwaz, J., Ecochard, R., \& Bérard, C. (2013). Responsiveness of 
the motor function measure in patients with spinal muscular atrophy. Archives of Physical Medicine and Rehabilitation, 94(8), 1555-1561. https://doi.org/10.1016/j.apmr.2013.01.0 14

Waldrop, M. A., \& Elsheikh, B. H. (2020). Spinal Muscular Atrophy in the Treatment Era. Neurologic Clinics. https://doi.org/10.1016/j.ncl.2020.03.002

Wang, C. H., Finkel, R. S., Bertini, E. S., Schroth, M., Simonds, A., Wong, B., ... Trela, A. (2007). Consensus statement for standard of care in spinal muscular atrophy. Journal of Child Neurology. https://doi.org/10.1177/08830738073057 88

Werlauff, U., Vissing, J., \& Steffensen, B. F. (2012). Change in muscle strength over time in spinal muscular atrophy types II and III. A long-term follow-up study. Neuromuscular Disorders, 22(12), 10691074. https://doi.org/10.1016/j.nmd.2012.06.35 2

Wijngaarde, C. A., Blank, A. C., Stam, M., Wadman, R. I., Van Den Berg, L. H., \& Van Der Pol, W. L. (2017). Cardiac pathology in spinal muscular atrophy: a systematic review. Orphanet Journal of Rare Diseases, 12(1), 1-10. https://doi.org/10.1186/s13023-0170613-5

Yeo, C. J. J., \& Darras, B. T. (2020). Overturning the Paradigm of Spinal Muscular Atrophy as Just a Motor Neuron Disease. Pediatric Neurology. https://doi.org/10.1016/j.pediatrneurol.20 20.01 .003

Yi, Y. G., Shin, H.-I., \& Jang, D.-H. (2020). Rehabilitation of spinal muscular atrophy: current consensus and future direction. Journal of Genetic Medicine, 17(2), 5561.

https://doi.org/10.5734/jgm.2020.17.2.55 